with perfect completeness in the space of a few square yards. Watersheds bounding contiguous basins, gently sloping plains, deeper valleys, steeply cut ravines may be recognised according as the rock varies here and there in more or less of cohesiveness.

The slight inequalities in this respect give rise to many other details worth noticing. On the vertical surface of the cliffs the rock is etched in a manner scarcely perceptible unless the sun shines obliquely on its surface. In this way a rock apparently homogeneous is seen to have been originally built up of layers deposited at the most various angles in the manner characteristic of what is called false bedding.

Here and there an undisturbed talus at the foot of a cliff has been permeated by water carrying some cementing material which feebly binds together again the incoherent sand. The base gets washed or blown away, and the surface of the talus is seamed with miniature landslips leaving steep and precipitous cliffs of the frightful height of at least two to three inches. These precipices are scored and columned with the sharpest fluting as they have been planed down by the subsiding soil (Fig. I reduced).

Here and there again the rock is traversed horizontally by layers, in which the cementing material is ferruginous. When the rock is denuded down to this it first gets washed pretty bare and then broken up into angular fragments by the frost. Each of these fragments protects the rock beneath, and so gradually gets mounted upon a little pedestal like the perched blocks of a Swiss glacier or the mud columns in the valley of Visp (Fig. 2, natural size).

T. D.

\section{PHYSICAL SCIENCE IN SCHOOLS}

THE struggle which Physical Science has had to 1 obtain a footing amongst the regular subjects of the school curriculum has not been altogether in vain, and the study of science now occupies a conspicuous place in the prospectus, at any rate, of many of our schools. But to those who, being behind the scenes, are acquainted with the real facts, the position which science occupies amongst other subjects, with a few honourable exceptions, is insignificant in the extreme. It is admitted as an axiom by all science teachers, that if the study of science is to be of any value, the student must, in some part at least of his work, be brought face to face with the facts of nature, and that unless this be the case the introduction of the subject into the school course is worse than useless; but how commonly does the so-called science-work of a school consist simply in the acquisition of so much "useful knowledge?" And even when in other respects the teaching is fairly satisfactory, the practical work is too often optional-an "extra," or taken on half-holidays, and so ruined by the competition of cricket and football.

We believe that a fair standard by which to judge of the present position of the study of science in schools is to be found in the "Regulations of the Oxford and Cambridge Schools Examination Board," and in the papers set at the examination for certificates (the first held) of July 1874 . Certificates are awarded to those who succeed in passing in a certain number of subjects; and the possession of such a certificate should indicate that a boy has obtained a thorough education up to the point fairly to be expected on leaving school.

Regulation 7 provides that "the examination for certificates shall include the following subjects :-

"Group I.-(1) Latin; (2) Greek ; (3) French and German.

"Group II.-(I) Mathematics (Elementary) ; (2) Mathematics (Additional).

"GroUp III.-(I) Scripture Knowledge ; (2) English ; (3) History.

"GROUP IV.-(I) Natural Philosophy ; (2) Heat and Chemistry ; (3) Botany; (4) Physical Geography and Elementary Geology.
Every candidate shall be required to satisfy the examiners in at least four subjects, taken from not less than three different groups."

From the foregoing Regulation, one would naturally suppose that equal value was attached to each of these subjects, an arrangement which would leave no room for the complaint that science did not receive its proper credit. Let us examine whether such is the case.

The examination papers show that out of more than fifty-two papers set, only four were set on scientific subjects. To pass in Latin it would seem that five different papers must be satisfactorily answered, in Greek four, in French and German eight, in Elementary Mathematics three, in Additional Mathematics four, in Scripture Knowledge three, in English three, in History one, in Natural Philosophy one, in Heat and Chemistry one, in Physical Geography one, in Botany one. We may not unfairly take these numbers as representing the relative value of the different subjects in the eyes of the compilers of the Regulations.

Thus, while a candidate who, having received his training in languages, selects, say Latin, French and German, English, and Elementary Mathematics, has to answer nineteen papers-the same certificate may be cheaply obtained from seven papers, by selecting Scripture Knowledge, Elementary Mathematics, Chemistry, and Physical Geography.

Next let us examine the kind of questions set. Elementary Mathematics means simply Arithmetic, Euclid, books i. and ii., and Algebra to simple equations. In Heat and Chemistry we find the following, amongst others (space does not permit to transcribe the whole paper).

I. Define "co-efficient of expansion." What relations subsist between the linear, superficial, and cubical expansion of a piece of iron?

2. Describe fully the successive changes which occur when a piece of ice is placed in an open vessel, and the vessel then gradually heated to, say, $150^{\circ} \mathrm{C}$.

3. What are our available sources of heat?

4. What degrees on the Centigrade scale correspond to $16^{\circ} \mathrm{R}$. and $-4^{\circ} \mathrm{F}$.? At what temperature will Fahrenheit and Centigrade thermometers give the same reading?

5. Distinguish between elements and compounds, and between compounds and mixtures.

6. What is the composition of the atmosphere? Give the outlines of a method for analysing it accurately. How is it proved to be a mixture and not a chemical compound?

7. I want to convert 132.4 grm. of lead nitrate into lead sulphate. How much potassium sulphate will effect this change, and how much lead sulphate shall I obtain? $(\mathrm{Pb}=207, \mathrm{~K}=39$.

In Physical Geography :-

r. How may the earth be proved to be a globe, and in what respects does it differ in form from a perfect sphere?

2. Show by examples how climate is affected by the position of a locality independently of the latitude?

3. Define the terms watershed, denudation. Give instances of denudation effected by rivers.

4. Explain the terms dip, strike, joints, and foults.

5. What is supposed to be the origin of coal, and on what facts is this supposition based ?

6. Name and describe fully the accompanying specimens :--

[Specimens: Granite, oolite, dolomite, selenite, and two bivalve fossils.]

It is to be remarked that, with the exception of the last question, there is no test of a practical kind at all. Is the knowledge of the composition of the air, of the reasons for believing that the earth is round, of the meaning of the terms watershed, dip, \&c, -is this the utmost that should be demanded of a boy of eighteen who has studied science instead of the older well-established subjects of classics and mathematics? 
Compare with this the extent of knowledge expected in other subjects. French and German, for example, together form one subject: to succeed, the candidate must be proficient in dictation in each language ; trans. lation from unseen authors; the grammar, history, and etymology of the languages; translation from English into French and German, besides translation from books appointed. For the last examination, books which might be chosen were-in French, Pascal's "Provincial Letters;" in German, Goethe's "Faust" and "Italiänische Reise,"

The relative value attached to different branches of science is also worthy of remark. Chemistry, for example, is supposed to be so far inferior to Botany as an educational study, that the slight subject of Heat is added as a make-weight.

It is really hard to determine whether the compilers of these Regulations (the head-masters of one or two of our most important schools being amongst them, if report errs not) have acted simply in ignorance of what physical science in a school ought to be, or whether this is an inge. nious device to strangle science as a school study, and to get rid of the obnoxious interloper by driving the weak and idle to it, and thus giving it a bad name as "the refuge of fools."

\section{N. Marshall WatTS}

\section{PROF. MAX MÜLLER}

$T \mathrm{~T}$ was decided at a Convocation held at Oxford on 1 Tuesday that an inducement sbould be offered to Prof. Max Müller to continue to honour Oxford by remaining connected with that University. It would certainly have been a disgrace had no effort been made to retain the services of so eminent a scholar, which other countries are eagerly anxious to obtain. The proposal made by the Dean of Christ Church, which was carried by a large majority, was to relieve Prof. Müller of the obligation to lecture, and to provide for the appointment of a deputy, who should receive one-half of the salary of the present Professor. This scheme is confessedly somewhat of a makeshift; time was of importance, and the proper course, by statute, because lengthy, was not available. Vienna had offered the Professor a Chair of Sanskrit and provision for the publication of his books; and to this offer an immediate answer was necessary. The present, the Dean wished it to be understood, was a provisional arrangement in view of impending changes. The Dean was authorised to state that the Government "Universities" Bill would constitute an Executive Commission, with powers to receive schemes from Colleges, and to base upon them the new University and Collegiate organisation. He pledged himself there should be an opportunity given for considering in constitutional form the permanent arrangement of the matter at present in hand. He defended the decree from the charge of robbing Comparative Philology, for Sanskrit studies were an essential part of it, and the arrangement would give an admirable opportunity for some young man to make out his claim to the Professorship. He could have wished the arrangement had been more liberal, but, in fact, the University had come to the end of its tether. The Dean then dwelt on the high value of the Professor's services. He told how Mr. Max Muiller had "audaciously" projected, when but a youth and a pupil of Burnouf, an edition of the Rigveda. For this he was forced to come to England, for which purpose he raised funds by translations, \&c. Bunsen, on whom he called without introduction, had forwarded him to Prof. Wilson, and the India House, with sagacious liberality, took him up. Dean Gaisford had bidden men read Homer, with some ancient commentator, as the key to Greek literature. If these had been only accessible in manuscript, involving the reading, indexing, and perpetual annotation of infinite other MSS., who would have undertaken the task? And this was what Max Müller had done. Dean Liddell knew not whether to admire and wonder at most-his ardour in commencing, his perseverance in continuing, or his genius in the execution of his work. With regard to a recent statement as to Prof, Muiller's future work, the Dean stated the fact to be that the University had accepted the offer of publishing a choice selection of translations from Sacred Books-at the utmost, twenty-four volumes. But this, it was obvious, was sufficient to prevent the Professor from enjoying the position of a sinecurist. The Dean concluded by enu. merating a list of the Professor's distinctions, and urged the University to keep him if it could, how it could, while it could.

We must say that most of those who spoke in the discussion which followed missed the freal point at issue. Prof. Max Miiller has already rendered such important services to Oxford, to England, and to Science, and proved himself so coinpetent to continue these services, that there should have been no hesitation whatever about endowing him sufficiently to enable him to continue his valuable researches unhampered. But we must be thankful for small mercies at present, hoping from the hint dropped by the Dean that better things are in store.

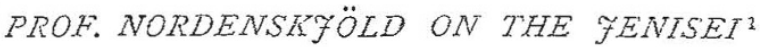

I HAVE before mentioned the great abundance of extraordi narily delicate varieties of fish which Jenisei yields, and that during our river joutney we made as complete a collection of them as possible. The steamer's terlious voyage was, besides, employed by me in collecting statenents regarding the names of the most important varieties, the price paid for them on the steamer, and their size,

\begin{tabular}{|c|c|c|c|c|c|c|c|c|c|}
\hline & & $\begin{array}{l}\text { Common } \\
\text { weiglit. } \\
\text { I3 } \mathrm{jb} \text {. }\end{array}$ & & $\begin{array}{l}\text { Gre } \\
\text { wei } \\
50\end{array}$ & $\begin{array}{l}\text { atest } \\
\text { ght, } \\
\text { lb. }\end{array}$ & & 80 & & rice. \\
\hline & $\begin{array}{l}\cdots \\
\ldots\end{array}$ & $\begin{array}{r}13 \\
6\end{array}$ & $\cdots$ & $\begin{array}{l}50 \\
25\end{array}$ & $11 \%$ & $\begin{array}{l}\cdots \\
\ldots\end{array}$ & $\begin{array}{l}80 \\
\text { ro }\end{array}$ & kop. & $\begin{array}{l}\text { per po } \\
\text { each. }\end{array}$ \\
\hline n & $\cdots$ & $I_{0}^{2}$ & $\ldots$ & 3 & $"$ & $\ldots$ & 2 & ", & \\
\hline & $\ldots$ & $4 \%$ & $\ldots$ & 12 & 3 & $\ldots$ & 9 & $"$ & " \\
\hline & .. & 16 & $\ldots$ & 80 & $"$ & $\ldots$ & - & & \\
\hline & $\ldots$ & $\begin{array}{r}3 \\
16\end{array}$ & $\cdots$ & $\begin{array}{r}30 \\
280\end{array}$ & $"$ ? & $\ldots$ & I 50 & kop. & per poo \\
\hline & .. & - & $\ldots$ & - & & $\ldots$ & 40 & & \\
\hline
\end{tabular}

The trade, however, is carried on here in this way, that the goods to be purchased are valued in coin, but pavment is made in goods at the merchant's valuation, on which account the true price is perhaps considerably below that which is here stated.

After the numerous crew on the Alexander and the "lodjors" had attended with great devoutness a festival service in the church of the monastery and a neighbouring chapel where the holy founder's dust and work-harness are preserved, after we had seen several of the remarkable things belonging to the monastery, and among them an exceedingly well-preserved Scla. vonic Bible from the sixteenth century, and after I had paid a visit, along with the captain, to an aged cripple who in his youth had made a pilgrimaye to Jerusalem, we steamed on. Our pro. gress, as was commonly the case, was slow, in consequence of the strong current and the frequent stoppages, which of course we turned to account by making excursions to examine the natural history of the region, by conversing with the inhabitants, \&c. The latter consist partly of Russians who have settled there, partly of natives, "Asiatics," who frequent the rivers during summer, partly on their own account, partly as employed by Russians. In such circumstances their dwellings consist of tents of quite the same form as the Lapp "kota." The Samoyede tent is commonly covered with reindeer skins, the Ostiak tent with birch bark. A number of dogs are always found in the neighbourhood of the tent, which during winter are used for general draught purposes, and in summer for towing up boats against the current-a means of transport on water which gxeatly surprised our seal-fishers. For this purpose a sufficient number of dogs are harnessed to a long line, one end of which is fastened to the stem of the boat. The dogs then go forward upon the level bank, where in this way

${ }_{2}^{x}$ Continued from p. 277 ;

2 Njelma, Tschir, Omul, and Muksum are varieties of the Gwyniad, Silj is the fry, or young, of the same fish. 